Artigo

\title{
Universidades Federais Brasileiras e o Impacto Regional do Reuni
}

Brazilian Federal Universities and Regional Impact of Reuni

Universidades Brasileñas Federales y el Impacto Regional de Reuni

\author{
Aline Vanessa Zambello ${ }^{1}$,
}

\footnotetext{
Filiação institucional. Bacharela em Ciências Sociais e mestra em Ciência Política pelo Programa de Pós Graduação em Ciência Política da Universidade Federal de São Carlos, São Carlos, SP, Brasil.

Correspondência: $\quad$ E-mail: alinezambello@gmail.com
}

Resumo Nos últimos dez anos observamos uma transformação importante no cenário universitário federal. A trajetória da educação superior no Brasil criou um panorama onde o setor privado prevaleceu e que cresceu desordenadamente entre as regiões na distribuição de vagas e instituições de ensino superior. Com a expansão recente das universidades federais por meio do programa REUNI, essas instituições assumem lugar de destaque nas políticas públicas para educação superior. Neste artigo trabalhamos com a hipótese de que o REUNI foi implementado no sentido de privilegiar o equilíbrio entre as regiões, dado presente nos documentos da política. Para tanto, faremos uma comparação entre os períodos 1994-2001 e 2002-2010. Como resultados do estudo apresentamos dois cenários distintos que se formam em relação ao número de vagas e instituições nas diferentes macrorregiões brasileiras. Nesse sentido, haveria, ainda que timidamente, o entendimento da função supletiva da União quanto a equalização das oportunidades educacionais conforme CF de 1988 art. 211.

Palavras-chaves: Política Pública; Ensino Superior; Universidades 
Federais; equilíbrio regional; REUNI;

Abstract Over the past decade, there was significant change in the federal university setting. The history of higher education in Brazil has created a panorama where the private sector prevailed and grew wildly between regions in the distribution of vacancies and higher education institutions. With the recent expansion of federal universities through REUNI program, these institutions are prominent place in public policies for higher education. In this article we are working with the hypothesis that the REUNI was implemented in order to privilege the balance between regions, as present in the policy documents. Therefore, we will compare the periods 1994-2001 and 2002-2010. As study results present two different scenarios that form in relation to the number of places and institutions in different Brazilian regions. In this sense, there would be, albeit timidly, the understanding of the supplementary function of the Union as the equalization of educational opportunities as Federal Constitution of 1988 art. 211.

Keywords: Public Policy; Higher Education; Federal Universities; Regional Balance; REUNI;

Resumen En la última década, se produjo un cambio significativo en el entorno universitario federal. La historia de la educación superior en Brasil ha creado un panorama en el que el sector privado se impuso y creció enormemente entre regiones en la distribución de las vacantes y las instituciones de educación superior. Con la reciente expansión de las universidades federales mediante el programa REUNI, estas instituciones asumen lugar destacado en las políticas públicas de educación superior. En este artículo se trabaja con la hipótesis de que el REUNI se implementó con el fin de privilegiar el equilibrio entre regiones, ya presente en los documentos de política. Por lo tanto, vamos a comparar los períodos 1994-2001 y 2002-2010. Como resultados del estudio presentan dos situaciones diferentes que se forman en relación con el número de vacantes e instituciones en diferentes regiones de Brasil. En este sentido, habría, aunque tímidamente, la comprensión de la función complementaria de la Unión como la igualdad de oportunidades educativas, Constitución Federal de 1988 art. 211.

Palabras Clave: Política Pública; Educación Superior; Universidades Federales; equilibrio regional; REUNI. 


\section{Introdução}

Nos últimos dez anos temos visto mudanças significativas no campo da educação superior no Brasil. A necessidade de expansão para atendimento de uma demanda crescente abriu possibilidade para que a expansão tenha ocorrido a partir do setor privado, principalmente nos anos 90, ainda que isso não tenha sido vinculada, publicamente, a uma política pública de Estado (NUNES, 2007).

Mais recentemente, uma mudança importante na estrutura das Universidades Federais a partir de políticas de expansão tem sido alvo de inúmeros estudos. As transformações advindas da expansão, de acordo com Marques \& Cepêda (2012) são da ordem: a) quantitativa, b) geográfica, c) de acesso e d) de funções. Do ponto de vista de uma mudança quantitativa o Programa de Apoio a Planos de Reestruturação e Expansão das Universidades Federais (REUNI) provocou uma expansão do número de vagas, de campi e de Instituições de Ensino Superior (IES), acompanhada de um espalhamento e ampliação da cobertura das IES pelo território nacional - incluindo as fronteiriças (nacional, internacional e áreas isoladas).

Ainda podemos considerar um passo na democratização de acesso a grupos sociais populares, promovendo a inclusão desses grupos antes afastados da educação superior, por meio de mecanismos inovadores de ingresso - tais como a adoção do Exame Nacional do Ensino Médio/ENEM, acesso via Sistema de Seleção Unificado/SiSU - pela adoção de políticas de reserva de vagas e de Ações Afirmativas, além do aumento dos recursos para acolhimento e permanência (Programa Nacional de Assistência Estudantil - PNAES). Eixos como promoção do desenvolvimento local, valorização das diferenças culturais e integração regional também estariam presentes nessa ampla proposta (vide documentos REUNI, PNE 2001;2011, PDE, LDB e a própria CF 88).

O REUNI tem pontos de contato importantes com marcos regulatórios como a Constituição de 1988, a LDB de 1996 (Lei 9394/96), o Plano Nacional de Educação/PNE de 2001, o Plano de Desenvolvimento da Educação/PDE (2007) e ainda as diretrizes internacionais presentes nos documentos da UNESCO $(1994 ; 1998)$. Mas, sem dúvida, correspondeu a uma decisão e conteve um projeto afinado com a agenda do governo federal sob direção do presidente Lula e do então ministro Fernando Haddad (como apontam o programa de governo petista "Uma escola do tamanho do Brasil" de 2002). Há metas amplas que indicam que associavam ao REUNI um potencial de transformação importante: a ampliação da possibilidade de acesso e permanência ao ensino superior, aumentando a malha institucional e também através de políticas de permanência e de ações afirmativas; levar as UFES para onde está o ator, capilarizando as capacidades institucionais são alguns exemplos.

As diretrizes e recursos do REUNI foram criados e apresentados para adesão ou não das UFES já existentes - quando o foco fosse expansão das universidades e não a criação de novos (neste caso era criada uma comissão 
local, em geral com a parceria de uma UFES tutora). O MEC acenou com o potencial de crescimento, sinalizando recursos para expansão física, de cursos e unidades, de vagas discentes, de funcionários, professores e instalações. As universidades que aderiram tinham uma margem de liberdade para escolhas (como períodos noturno/diurno, cursos, metas internas) que eram recompensadas pelo governo quanto mais se aproximassem das diretrizes traçadas - por exemplo, recursos maiores para graduações noturnas, licenciaturas ou engenharias (dependendo do entorno), etc. Formou-se assim um cenário complexo de avaliação da implementação real do REUNI, já que de um lado a fixação dos objetivos do MEC eram mais claros que as opções e aplicações efetivas realizadas em cada IES. Balizaram essa estratégia tanto a preservação dos projetos de expansão para atendimento das necessidades locais quanto o reconhecimento da autonomia universitária. O Governo Federal fez a chamada, estabeleceu as regras e definiu os recursos; as UFES interessadas em participar desenvolveram seus próprios projetos. O resultado final não é homogêneo e revela muito da tensão entre a proposta original e o chão da realidade local. $E$ podem ter pesado nesse resultado o tamanho, envergadura, prestígio, localização (estado, região, entorno) e rede de cada UFES, bem como dos grupos que constituíram as novas instituições criadas (como a UFABC, Unila, UFFS, UFT, entre outras), como já considerado em Marques \& Cepêda (2012); Cepêda (2012) e Cepêda (2014).

Este estudo procura investigar como as transformações da estrutura recente das Universidades Federais impactam na questão do equilíbrio regional. Trabalhamos com a hipótese de que, no período compreendido entre 2002-2010, essas transformações, viabilizadas pelo REUNI, levam a uma maior distribuição equitativa (ainda que não equilibrem de forma ideal, todo o cenário nacional) da estrutura das Universidades Federais.

Para efeito comparativo faremos o mesmo levantamento para o período anterior, entre 1994 e 2001 na gestão de FHC.

Para tanto, levantamos dados secundários de forma a comparar a relação entre a "oferta" dada pela disponibilidade de vagas nas Universidades Federais, dados obtidos no INEP/MEC e a "demanda" aqui indicada de duas formas: a) demanda potencial: população (18-24 anos), indicador utilizado internacionalmente para medir abrangência da educação superior; b) demanda dos concluintes do Ensino Médio, ou seja, população apta a entrar no ensino superior. A comparação tem intuito de analisar dois cenários. O primeiro situado entre 1994 e 2001 que, apostou no crescimento das IES privadas e que não apresentou ação estatal para as Universidades Federais e o segundo, 2002 a 2010, com a presença do REUNI. Ressaltamos que além do REUNI nesses períodos estão compreendidos duas gestões federais de partidos diferentes que tem, ao nosso ver, projetos públicos diferentes para a educação superior. Ainda que nosso foco principal não seja elaborar uma análise da forma e conteúdo desses projetos, apresentamos um estudo comparativo dos períodos no qual 
buscamos delinear diferenças importantes no que tange as políticas voltadas para a questão da educação superior pública federal.

Dessa forma, através do cenário comparativo buscamos evidências para tendência de equalização do atendimento à demanda entre as diversas regiões. Além disso, também levantamos questionamentos quanto a futuras pesquisas no campo, as quais poderão seguir a partir do cenário levantado nesse estudo.

\section{A trajetória da educação superior no Brasil}

A trajetória do ensino superior no Brasil possibilitou a conformação de duas naturezas administrativas das IES, ou são operadas pelo Estado (público) ou pelo Mercado (privado ${ }^{1}$ ). Nos últimos 80 anos (Barreyro, 2008; Durham, 2003) a trajetória das Instituições de Educação Superior (IES) apostou no fortalecimento do modelo privado de ensino, ainda que isso não seja publicamente declarado enquanto opção política (Nunes, 2007).

Em uma breve revisão da trajetória da educação superior no Brasil, podemos indicar como ponto inicial da educação superior, a vinda da família real em 1808, assim, as primeiras IES começam a aparecer em forma de instituições isoladas e de pequeno porte. O modelo de Universidades (agregação de institutos ou centros) data de 1931 com o Estatuto das Universidades Brasileiras (Decreto 19.851/31) e que segue vigente até 1961 .

Na década de 30 nota-se a criação de duas grandes universidades, a USP 1931 e a Universidade do Distrito Federal (no Rio de Janeiro) - 1935, as duas com finalidades políticas (CUNHA, 1980) bem como as Universidades Católicas, cada uma delas com um projeto político diferente no que tange a missão e estrutura das universidades. Nesse sentido, houve uma tensão entre uma elite católica conservadora e intelectuais liberais. O modelo de universidade até então não tinha como parâmetro a pesquisa e produção de conhecimento, estava mais voltada para a formação/instrução de carreiras, em geral e especialmente daquelas tradicionais como direito, medicina e engenharia.

O modelo adotado entre 1930 até a década de 60 era pautado nas instituições públicas de ensino, que além da criação de universidades públicas mitigava o avanço do setor privado e que a partir da década de 50 até a década de 60, muitas instituições privadas se tornam federais.

${ }^{1}$ A categoria de instituições privadas ainda podem ser dividas entre aquelas com fins lucrativos e sem fins lucrativos. 
Durante o período entre 1945 e 1964 foram criadas 22 novas Universidades Federais, sendo que cada unidade federativa agora contava com uma instituição. Além disso, foram criadas 9 universidades religiosas, sendo que dessas 1 era presbiteriana e 8 eram católicas. Ampliando assim o sistema que havia iniciado em 30 (SOARES, 2002).

Após a Segunda Guerra Mundial, os Estados Unidos passou a oferecer ajuda sistemática aos países Latino Americanos tendo em vista o estancamento de possíveis países alvo da União Soviética. Para isso, lançou mão de diversos programas de ajuda, no Brasil - com a anuência do Regime Militar - a cooperação abrangeu várias áreas, entre elas a educação superior o chamado acordo MECUSAID (United States Agency for International Development). Esse acordo fomentou mudanças no formato como a universidade no Brasil estava organizada.

Em 1966, o professor Rudolph Atcon elaborou um relatório sobre a universidade no Brasil e que apontava que ela deveria estar organizada em sintonia com o mercado, visando a formação de mão-de-obra qualificada para tal fim, além de propor assessoria àquelas instituições que se interessassem visando uma reorganização administrativa.

Em 1968 aprovada a Lei da Reforma Universitária (Lei 5.540/68) que estabeleceu uma série de mudanças que se aplicavam às instituições federais, porém, por depender de recursos públicos, as instituições privadas também incorporaram essas mudanças.

A partir de 1968, com o resultado do milagre econômico a necessidade de mão-de-obra aumentou e, consequentemente a pressão por vagas. Nesse sentido, as instituições privadas foram se expandindo no atendimento dessa demanda principalmente na periferia de grandes metrópoles e em cidades de médio porte no interior dos estados mais desenvolvidos (SOARES, 2002).

A aprovação da LDB de 1961 (que substituiu o Estatuto das Universidades Brasileiras) mudou o modelo vigente incluindo itens como: a) unificação do vestibular; b) carreiras de curta duração; c) matrículas em formato de crédito; d) sistema de pós-graduação; e) instituição de departamentos; f) carreira docente baseada em títulos e méritos; g) dedicação exclusiva.

Na década de 70 o impulso expansionista observado é dado principalmente por instituições privadas de ensino, ainda que na segunda metade da década o crescimento tenha sido negativo, ou seja, houve uma diminuição no número de instituições, a diminuição do setor privado foi menor, em termos percentuais, que a do setor público. No contexto econômico e político a partir da segunda metade da década de 70 temos o princípio do que foi a crise de hiperinflação nos anos 80 , os vários planos para tentativa de estabilização da inflação até meados dos anos 90, quando o plano Real estabiliza a econonomia, porém, por todo esse período, para conseguir minimamente com que esses 
planos fossem colocados em prática o Estado teve que cumprir com metas de redução de despesas e ajustes de custos (BAER, 2002; GREMAUD, VASCONCELLOS \& TONETO Jr, 2007), o que claro, atingiu a educação tanto nos setores públicos quanto privados.

Tabela 1: Número de IES nos anos de 1971, 1975 e 1980 por categoria administrative

\begin{tabular}{lrrrr}
\hline Ano & Público & Privado & $\begin{array}{l}\Delta \% \\
\text { Público }\end{array}$ & $\begin{array}{c}\Delta \% \\
\text { Privado }\end{array}$ \\
\hline $\mathbf{1 9 7 1}$ & 112 & 527 & & - \\
$\mathbf{1 9 7 5}$ & 128 & 732 & $14,28 \%$ & $38,90 \%$ \\
$\mathbf{1 9 8 0}$ & 109 & 684 & $-14,84 \%$ & $-6,56 \%$ \\
\hline
\end{tabular}

Fonte: Baseado em Barreyro, 2010 p. 20

No número de vagas também é possível perceber a predominância das instituições de ensino privado durante a década de 70:

Tabela 2: Evolução das matrículas na educação superior de graduação presencial, por categoria administrativa (1960-1979)

\begin{tabular}{|c|c|c|c|c|c|c|}
\hline Ano & Pública & Privada & $\begin{array}{c}\Delta \% \\
\text { Pública }\end{array}$ & $\begin{array}{c}\Delta \% \\
\text { Privada }\end{array}$ & Total & $\begin{array}{c}\Delta \% \\
\text { Total }\end{array}$ \\
\hline 1960 & 52.000 & 41.000 & 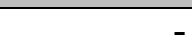 & - & 93.000 & \\
\hline 1970 & 210.613 & 214.865 & 305,02 & 424,06 & 425.478 & 357,50 \\
\hline 1971 & 252.263 & 309.134 & 19,77 & 43,87 & 561.397 & 31,94 \\
\hline 1972 & 278.411 & 409.971 & 10,36 & 32,62 & 688.382 & 22,62 \\
\hline 1973 & 300.079 & 472.721 & 7,78 & 15,30 & 772.800 & 12,26 \\
\hline 1974 & 341.028 & 596.565 & 13,65 & 26,20 & 937.593 & 21,32 \\
\hline 1975 & 410.225 & 662.323 & 20,29 & 11,02 & 1.072 .548 & 14,39 \\
\hline 1976 & 404.563 & 692.164 & $-1,38$ & 4,50 & 1.096 .727 & 2,54 \\
\hline 1977 & 409.479 & 749.567 & 1,21 & 8,29 & 1.159 .046 & 5,68 \\
\hline 1978 & 452.353 & 773.204 & 10,47 & 3,23 & 1.225 .557 & 5,74 \\
\hline 1979 & 462.303 & 849.496 & 2,20 & 9,86 & 1.377 .799 & 12,42 \\
\hline
\end{tabular}

Fonte: Baseado em Pinto (2004) com dados do MEC/INEP

Segundo Durham (2003) a expansão do lado privado do ensino superior da década de 70 pode ser explicada por: a) mudança da legislação pertinente a qual permite o funcionamento de pequenas instituições com fins lucrativos e b) havia uma demanda reprimida de egressos do ensino médio que ainda não tinham entrado no ensino superior e também aqueles que agora faziam o supletivo. Aliado a isso, o ensino privado disponibilizou vagas e cursos noturnos, criando uma demanda.

Como já dito, nos anos 80 temos o período de transição política e de grave crise econômica. Dado o perfil das instituições privadas de ensino até então, a crise cria uma estagnação na criação de vagas e instituições. A estratégia, então, utilizada pelas instituições privadas foi se organizar em agrupamentos do tipo Faculdades ou Faculdades Integradas ao invés de estabelecimentos isolados, que 
permitiam, pelo tamanho aumentado, podem manejar vagas e cursos de forma a atender rapidamente a demanda de mercado.

Tabela 3: Número de instituições privadas de ensino superior por tipo de organização acadêmica (1980-1994)

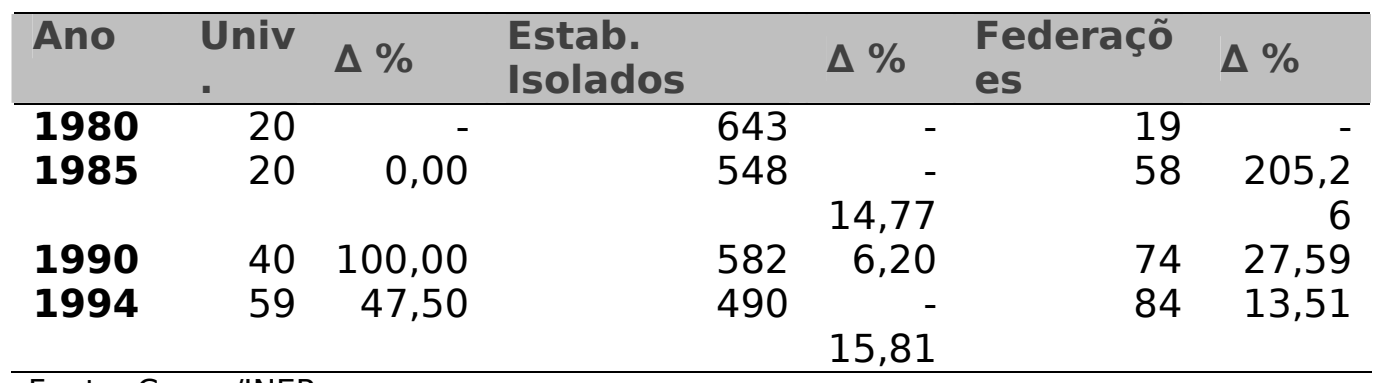

Fonte: Censo/INEP

O crescimento no setor público significativo entre o ano de 1980 e 1981 é dado pelas universidades estaduais (crescimento de 17,52\%) e entre 1985 e 1986 o crescimento está localizado nas universidades municipais (16,74\%).

No contrapé desse processo, o ensino superior público no Brasil tem uma natureza diferenciada, as IES são consideradas instituições de excelência, principalmente pela produção científica das pós-graduação, embora estejam em número menor. Nesse sentido, há uma distribuição hierárquica entre Universidades (majoritariamente públicas) e Não-Universidades. Não consideramos aqui o caso dos Centros Universitários que administrativamente tem características diferentes das Universidades. Para mais informações sobre Centros Universitários consultar Nunes (2012).

\section{O Lugar da Educação Superior Pública}

A educação superior pública, em especial as Universidades, tem um lugar particular na produção acadêmica do conhecimento. Segundo dados do GeoCAPES, em 2013, 81,2\% dos programa de pós-Graduação estavam em estabelecimentos Federais ou Estaduais (sendo no total 2.829). Destes, 45\% estão na região Sudeste, $23 \%$ no Nordeste, $17 \%$ no Sul, $9 \%$ no Centro-Oeste e $6 \%$ no Norte. Assim, a maior parte dos programas se concentra na região Sudeste. Juntamente a isso, segundo dados do Painel Lattes, hoje, 49,52\% dos doutores exercendo atividades de Ensino e Pesquisa estão na Região Sudeste, $20,05 \%$ no Sul, $17,60 \%$ no Nordeste, 9,64 no Centro-Oeste e 4,16\% no Norte. Esses dados são importantes por apontar que a "força-trabalho" de pesquisa e desenvolvimento do país tem localização definida, sendo esse estratégico para desenvolvimento de tecnologia de ponta, importantes para alavancagem do desenvolvimento. 
Além disso, a educação. Segundo o estudo do IPEA (2010) aponta tem um fator multiplicador do PIB no qual o gasto equivalente a $1 \%$ do PIB faz com que 0 próprio PIB aumente em $1,85 \%$ e a renda familiar em $1,67 \%$. Sendo que o gasto com educação é o que tem maior efeito entre todos os tipos de gasto sobre o crescimento do PIB e das famílias.

Outros estudos apontam resultados interessantes na relação entre educação e: renda CORBUCCI (2011); POCHMAN (2004); renda e trabalho PERES (2010).

As IES públicas não são constituídas como uma categoria única e homogênea, elas estão dividas em: a) municipais; b) estaduais e; c) federais.

A criação e manutenção das IES em cada um dos níveis estão pautados na disponibilidade de captação e utilização de recurso também vinculado a cada um dos níveis. O que vemos é que durante a trajetória do ensino superior houve unidades federativas que conseguiram aportar grande montante de recurso para utilização no ensino superior, como no o caso de São Paulo, Rio de Janeiro, Minas Gerais e Rio Grande do Sul, mas isso não reflete a realidade da federação brasileira.

Assim, temos uma primeira assimetria: IES publicas se utilizam de fundos públicos estaduais para sua criação e manutenção. No caso das federais elas utilizam recursos públicos do governo federal e, por tanto, como descrito no artigo 211 da Constituição de 1988 deveriam ser aportados nas regiões conforme necessidade de equilíbrio federativo.

Deste modo, é um problema legítimo e fundamental o desenho regional das Instituições Federais de Ensino Superior, mais precisamente das Universidades Federais ${ }^{2}$ dado que o fundo público federativo deveria trabalhar nas categorias de: a) Isonomia e b) equidade ${ }^{3}$. Ou seja, distribuir os recursos captados coletivamente de forma a transformar os mais desiguais em mais iguais.

Na falta de uma lei orgânica da educação superior, temos a constituição federal de 1988 e a Lei de Diretrizes e Bases da Educação de 1996 que definem o papel na educação para União, estados e municípios. A educação superior deve ser legislada e fiscalizada pela União, que também poderá manter IES. Outras IES, estaduais ou municipais podem receber auxilio da união, mas devem ser mantidas com recursos vindos da sua instância. Devido ao cenário complexo que se coloca, e pela proeminência do Programa de Reestruturação das

2 Outros modelos como os Institutos Federais de Ensino Tecnológico tem uma dinâmica de funcionamento diferente e por isso não serão abordados nesse trabalho.

${ }^{3}$ A equidade é diferente da igualdade. 
Universidades Federais (REUNI) escolhemos como ponto de análise as Universidades Federais.

\section{Entre dois Cenários: Universidades Federais no Brasil em Dois}

\section{Momentos}

São dois cenários diferentes que comportam a questão da educação superior pública federal em seu aspecto de distribuição regional. Elencamos o primeiro período, durante a gestão FHC (1994-2001) e o segundo, durante a gestão Lula (2002-2010) buscando entender como a distribuição de vagas e IES se deu durante cada um dos períodos. Entendemos que no primeiro período a atuação do governo federal se deu no sentido de ações voltadas, principalmente, para setor privado de educação enquanto que no segundo período houve ações voltadas tanto para o setor privado quanto para o público.

A escolha desses períodos não foi ocasional nem aleatória. A partir de 1994 temos período de estabilização econômica, o que tira o país do cenário de incertezas e recuo como aquele apresentado principalmente após a segunda metade da década de 70, também incluímos nesse período a conversão do Conselho Federal de Educação para o Conselho Nacional de Educação em 1995, o qual trouxe estabilidade de atuação do órgão conforme indicado em Barbosa (2012) e ainda a políticas como o Financiamento Estudantil - FIES.

O segundo período está relacionado às políticas mais incisivas na educação superior federal pública, que inclui o programa REUNI, que foi protagonista na expansão das Universidades Federais e vai até 2010 por ser no momento, o ano no qual os dados secundários se encontram consolidados. Mas também apresenta ações para o setor privado como o Programa Universidade para Todos - PROUNI.

Além disso, os dois períodos são pertinentes a dois governos federais que tem projetos políticos diferentes no que tange as políticas públicas para a educação superior pública federal.

A partir de dados secundários construiremos dois cenários de análise, os quais tentarão evidenciar dois momentos distintos:

a) o primeiro, de assimetria regional, onde não havia regularidade, padrão ou dimensionamento na distribuição das IES e vagas das Universidades Federais em relação à demanda, isto é, pessoas aptas a cursarem a educação superior, que medimos enquanto demanda potencial (pessoas de 18-24 anos). Isso devido a dois motivos: em parte pelo atendimento do setor privado, principalmente em regiões onde o alunado pode arcar com os custos de formação e parte por não haver um projeto que orientasse crescimento das Universidades Federais;

b) o segundo, orientado pelo início do processo de simetria regional, e que, através de um programa orientado politicamente para melhor distribuição dos 
recursos (UFES e vagas) entre as regiões, privilegiando principalmente àquelas com menor poder de atendimento via estabelecimentos estaduais, municipais.

Nesse sentido, apresentaremos dados de forma a iluminar esses dois cenários das Universidades Federais, indicando que, a atuação do Programa REUNI pode ter colaborado com uma melhor distribuição dessas instituições e vagas entre as regiões. Item esse que merece aprofundamento de estudo.

\subsection{Entre 1994 e 2001 - Cenário de Assimetria Regional}

Nesse período percebemos uma assimetria entre as regiões no que tange a distribuição de recursos que consideramos importante para o funcionamento do sistema federal de educação superior, como criação de instituições e vagas em comparação com a demanda potencial de cada localidade. Entendemos que do lado da "demanda", pessoas de 18-24 anos representando uma demanda potencial de entrada na educação superior e do lado da "oferta" número de instituições e vagas. Além disso, é possível perceber que não houve alteração no número de Universidades Federais no período, permanecendo as mesmas em todas as regiões.

A demanda potencial nesse período permanece sem grandes alterações, ou seja, a população de 18 a 24 anos conforme apresentado na Tabela 4.

Tabela 4: População com idade entre 18 e 24 anos e a distribuição percentual entre as regiões (1994, 1996, 1998, 2000 e 2001)

\begin{tabular}{|c|c|c|c|c|c|c|c|c|c|c|}
\hline & \multicolumn{2}{|c|}{1994} & \multicolumn{2}{|c|}{1996} & \multicolumn{2}{|c|}{1998} & \multicolumn{2}{|c|}{2000} & \multicolumn{2}{|c|}{2001} \\
\hline & $\mathrm{N}$ & $\%$ & $\mathrm{~N}$ & $\%$ & $\mathrm{~N}$ & $\%$ & $\mathrm{~N}$ & $\%$ & $\mathrm{~N}$ & $\%$ \\
\hline Bras & 14.171. & 100, & 20.717 .96 & 100 & 21.365 .94 & 100, & 23.378 .83 & 100 & 23.746 .72 & \\
\hline il & 800 & 0 & 1 &, 0 & 5 & 0 & 1 &, 0 & 4 & 100 \\
\hline $\mathbf{N}$ & 969.653 & 6,8 & 1.586 .199 & 7,7 & 1.669 .179 & 7,8 & 1.894 .680 & 8,1 & 1.946 .044 & 8,19 \\
\hline NE & $\begin{array}{r}3.992 .1 \\
34\end{array}$ & 28,2 & 6.010 .216 & $\begin{array}{r}29, \\
0\end{array}$ & 6.157 .576 & 28,8 & 6.809 .689 & $\begin{array}{r}29, \\
1\end{array}$ & 6.896 .302 & $\begin{array}{r}29,0 \\
4\end{array}$ \\
\hline CO & $\begin{array}{r}1.023 .8 \\
22\end{array}$ & 7,2 & 1.504 .951 & 7,3 & 1.577 .977 & 7,4 & 512 & 7,2 & 1.727 .770 & 7,28 \\
\hline SE & $\begin{array}{r}6.071 .7 \\
20\end{array}$ & 42,8 & $8.6 \mathrm{~s}$ & $\begin{array}{r}41, \\
0\end{array}$ & 049 & 41,9 & 421 & $\begin{array}{r}41 \\
9\end{array}$ & 9.933 .323 & $\begin{array}{r}41,8 \\
3\end{array}$ \\
\hline $\mathbf{S}$ & $\begin{array}{r}2.114 .4 \\
71\end{array}$ & 14,9 & 2.919 .513 & $\begin{array}{r}14, \\
1\end{array}$ & 3.003 .164 & 14,1 & 3.196 .529 & $\begin{array}{r}13, \\
7\end{array}$ & 3.243 .285 & $\begin{array}{r}13,6 \\
6\end{array}$ \\
\hline
\end{tabular}

Tabela 5: População com idade entre 18 e 24 anos e a distribuição percentual entre as regiões (2002, 2004, 2006, 2008 e 2010) 


\begin{tabular}{|c|c|c|c|c|c|c|c|c|c|c|}
\hline & \multicolumn{2}{|c|}{2002} & \multicolumn{2}{|l|}{2004} & \multicolumn{2}{|c|}{2006} & \multicolumn{2}{|c|}{2008} & \multicolumn{2}{|c|}{2010} \\
\hline & $\mathrm{N}$ & $\%$ & $\mathrm{~N}$ & $\%$ & $\mathrm{~N}$ & $\%$ & $\mathrm{~N}$ & $\%$ & $\mathrm{~N}$ & $\%$ \\
\hline Brasil & 24.064 .848 & 100 & 24.700 .165 & 100 & 25.787 .745 & 100 & 24.581 .048 & 100 & 23.878 .186 & 100 \\
\hline $\mathbf{N}$ & 1.984 .804 & 8,25 & 2.068 .389 & 8,37 & 2.211 .423 & 8,58 & 2.173 .533 & 8,84 & 2.182 .614 & 9,14 \\
\hline NE & 6.971 .377 & 28,97 & 7.120 .610 & 28,83 & 7.376 .474 & 28,60 & 7.506 .301 & 30,54 & 7.023 .698 & 29,41 \\
\hline $\mathrm{CO}$ & 1.760 .116 & 7,31 & 1.824 .649 & 7,39 & 1.935 .079 & 7,50 & 1.792 .362 & 7,29 & 1.803 .673 & 7,55 \\
\hline SE & 10.067 .576 & 41,84 & 10.327 .270 & 41,81 & 10.771 .601 & 41,77 & 3.590 & 39,56 & 4.518 & 40,22 \\
\hline $\mathbf{S}$ & 3.280 .975 & 13,63 & 3.359 .247 & 13,60 & 3.493 .168 & 13,55 & 3.385 .262 & 13,77 & 3.263 .683 & 13,67 \\
\hline
\end{tabular}

Fonte: DataSus

Gráfico 1: Evolução da relação (\%) entre disponibilidade de vagas (oferecidas em processo seletivo) em UFES e demanda potencial (18-24 anos) entre 1994 e 2010

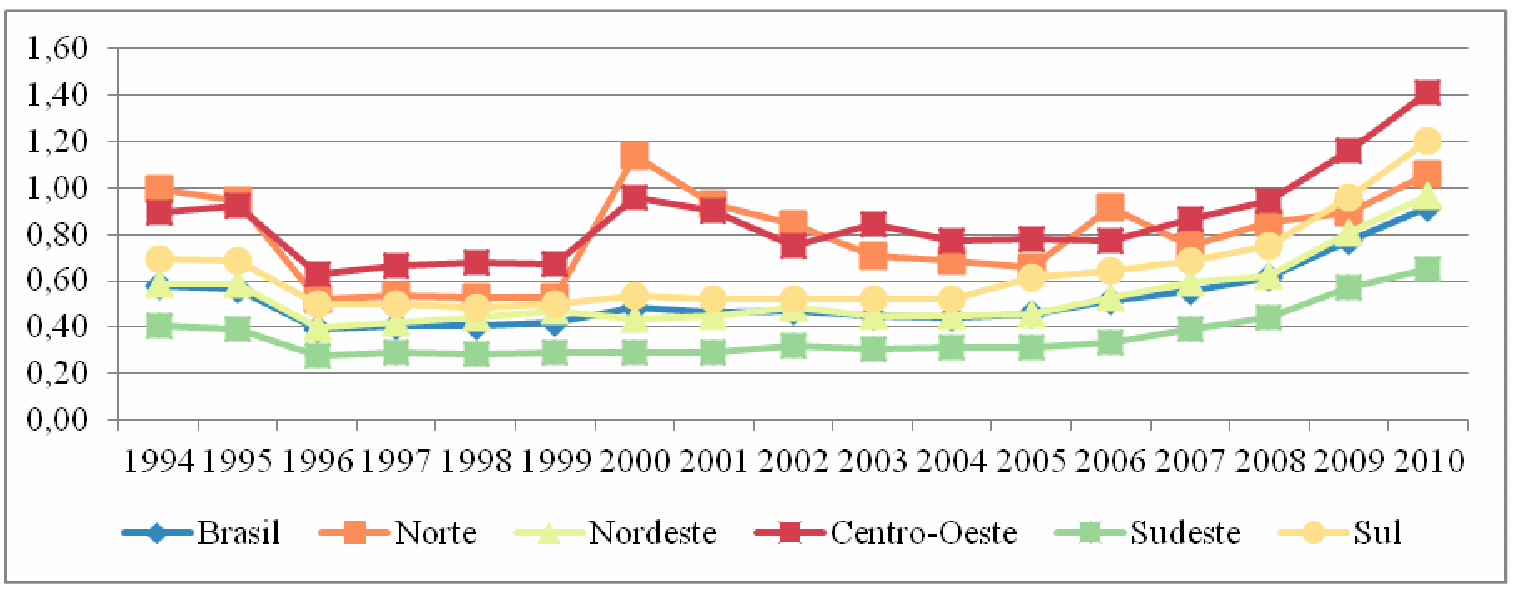

Fonte: Da autora Elaborado com dados da Sinopse da Educação Superiore DataSus

Em termos de instituições, o período não registra nenhuma alteração, ou seja, nenhuma nova Universidade Federal é criada no período, permanecendo estagnado. O quadro não se repete em termos de IES privadas, elas quase dobraram no período, indo de 617 a 1208 no total, sendo que seu maior crescimento se dá em regiões antes pouco abrangidas por esse sistema de ensino, ou seja, o nordeste, o norte e o centro-oeste. Regiões como o Sul e Sudeste tem crescimento, porém, em ritmo menor:

Tabela 6: Número de IES privadas em 1994 e 2001 por macroregião

\begin{tabular}{lrrr}
\hline & 1994 & 2001 & Cresc. \\
\hline Brasil & 617 & 1208 & $95,78 \%$ \\
\hline Norte & 11 & 49 & $345,00 \%$ \\
Nordeste & 33 & 165 & $400,00 \%$ \\
Centro-Oeste & 50 & 145 & $190,00 \%$ \\
Sudeste & 445 & 667 & $49,89 \%$ \\
Sul & 78 & 182 & $133,33 \%$ \\
\hline Fonte: INEP/MEC & & &
\end{tabular}


Quando comparamos o número de vagas disponibilizadas por processo seletivo pelas IES privadas e as inscrições feitas, vemos que a partir de 1995 a tendência é de que o aumento de vagas nessas IES cresce em ritmo maior do que a procura do alunado, sendo assim, se as inscrições em 95 , cobriram $81,53 \%$ das vagas disponíveis, em 2001 foram 68,76\% e diminui ainda mais, chegando a $44,18 \%$ em 2010. Houve sim aumento de vagas nas IES privadas, porém, em uma primeira mirada também houve saturação desses "novos mercados" onde as instituições se estabeleceram durante a década de 80 e 90.

Quando olhamos as vagas disponibilizadas pelas Universidades Federais no mesmo período não tem distribuição regular, conforme pode ser observado na Tabela 7 seguem tendência de crescimento ao longo do período. A curva das vagas acelera o crescimento a partir dos anos 2000, item que será avaliado no próximo tópico.

Tabela 7: Vagas oferecidas em processos seletivos em Universidades Federais por macro região 1994-2001

\begin{tabular}{lrrrrrrrr}
\hline & 1994 & 1995 & 1996 & \multicolumn{1}{c}{1997} & 1998 & 1999 & 2000 & 2001 \\
\hline Brasil & 81.681 & 81.548 & 80.693 & 85.178 & 86.864 & 90.937 & 112.826 & 116.928 \\
\hline Norte & 9.682 & 9.397 & 8.266 & 8.761 & 8.826 & 9.075 & 21.607 & 18.093 \\
Nordeste & 23.356 & 23.651 & 24.128 & 25.712 & 27.123 & 29.357 & 29.437 & 31.191 \\
Centro-Oeste & 9.156 & 9.677 & 9.512 & 10.293 & 10.677 & 10.845 & 16.189 & 15.534 \\
Sudeste & 24.837 & 24.084 & 24.125 & 25.653 & 25.749 & 26.472 & 28.536 & 29.095 \\
Sul & 14.650 & 14.739 & 14.662 & 14.759 & 14.489 & 15.188 & 17.057 & 17.015 \\
\hline
\end{tabular}

Fonte: INEP/MEC

As vagas também não apresentam padrão de homogeneização ou de equilíbrio entre as regiões, sendo que a sua distribuição chega a ser desfavorável em algumas regiões.

Em termos de cobertura, dada aqui pela relação entre vagas disponibilizadas nas Universidades Federais e a demanda potencial, percebemos no Gráfico 1 que mostra para o primeiro período houve redução nessa relação, ficando, na média nacional em 0,5\%, à exceção das regiões Norte e Centro-Oeste que tiveram um número expressivo de vagas criadas entre 1999 e 2000, sendo que na primeira foi de 9.075 vagas em 99 para 21.607 no ano seguinte e na segunda região foi de 10.845 para 16.189. Ainda que não seja foco deste trabalho aprofundar nesse ponto específico, Cunha (2003) aponta que no período FHC, período que estamos analisando, foi marcado por uma reconfiguração dada pela reforma do Estado que atingiu as Universidades Federais que tiveram recursos diminuídos de um lado e de outro a pressão da demanda por mais 
vagas fez com que essas instituições expandissem via abertura de vagas em cursos noturnos (BITTAR, OLIVEIRA e LEMOS, 2011).

Além da demanda potencial, é importante também visualizarmos a situação dos concluintes do Ensino Médio, que segundo Abreu (2010), sofreu grandes alterações devido a uma importante ação nos anos 90 no ensino médio brasileiro no sentido da expansão e visando prover garantias de conclusão.

Portanto, podemos aqui indicar uma medida de Concluintes por Vaga em Universidade Pública Federal para termos uma ideia de como se distribui ao longo das macrorregiões brasileiras:

Tabela 8: Distribuição de concluintes por vaga (oferecida em processo seletivo) entre as macrorregiões nos anos de 1994 e 2002

Fonte: Dados da Sinopse da Educação Superior e da Educação Básica INEP/MEC

\begin{tabular}{|c|c|c|c|c|c|c|}
\hline & \multicolumn{3}{|c|}{1994} & \multicolumn{3}{|c|}{2002} \\
\hline & vagas & $\begin{array}{l}\text { Conc } \\
\text { EM* }\end{array}$ & $\mathrm{c} / \mathrm{v}^{* *}$ & vagas & $\begin{array}{l}\text { Conc } \\
\text { EM* }\end{array}$ & $\mathrm{c} / \mathrm{v}^{* *}$ \\
\hline Brasil & 81.681 & 917.298 & 11,23 & 113.263 & 1.855 .419 & 16,38 \\
\hline Norte & 9.682 & 51.052 & 5,27 & 16.755 & 127.190 & 7,59 \\
\hline $\begin{array}{l}\text { Nordeste } \\
\text { Centro- }\end{array}$ & 23.356 & 203.863 & 8,73 & 33.587 & 466.435 & 13,89 \\
\hline Oeste & 9.156 & 61.468 & 6,71 & 13.260 & 121.324 & 9,15 \\
\hline Sudeste & 24.837 & 472.725 & 19,03 & 32.509 & 884.109 & 27,19 \\
\hline Sul & 14.650 & 128.190 & 8,75 & 17.152 & 256.361 & 14,95 \\
\hline
\end{tabular}

A partir dos dados mostrados na tabela 8, podemos perceber que apesar da tendência de aumento das vagas, o que temos é um inchamento na proporção de concluintes do ensino médio em relação ao número de vagas disponibilizadas pelas Universidades Federais.

Reiteramos que utilizamos essa medida como forma de demonstrar a dispersão das vagas em relação à demanda local, sabemos, no entanto, que o atendimento da população de interesse não se dá somente pelo acesso às universidades federais. Existem outras Instituições que atendem a formação da educação superior, as quais não são o foco dessa análise. 


\subsection{Entre 2002 e 2010 - Cenário de amenização das assimetrias regionais}

O segundo período conta com a atuação do Programa de Reestruturação das Universidades Federais, o REUNI que começa a ser implantado em 2007 e teve como premissa a busca pelo equilíbrio regional. Buscamos então verificar se houve uma melhor distribuição de recursos como vagas e instituições em relação às demandas locais.

Em termos gerais, podemos perceber através do Gráfico 2 que o movimento de crescimento do número de universidades federais já pode ser percebido em 2002, mas que alcança o seu ponto máximo entre 2006/2007.

Quando verificamos a relação entre vagas disponíveis nas Universidades Federais e a demanda potencial (Gráfico 1) é possível perceber que a partir de 2006 começa a crescer e mantém tendência de crescimento. É nesse período que temos o programa REUNI que previu a criação de novas Universidades, aumento de vagas, contratação de funcionários e aumento dos recursos.

\section{Gráfico 2: Número de Universidades Federais por região 1996-2011}

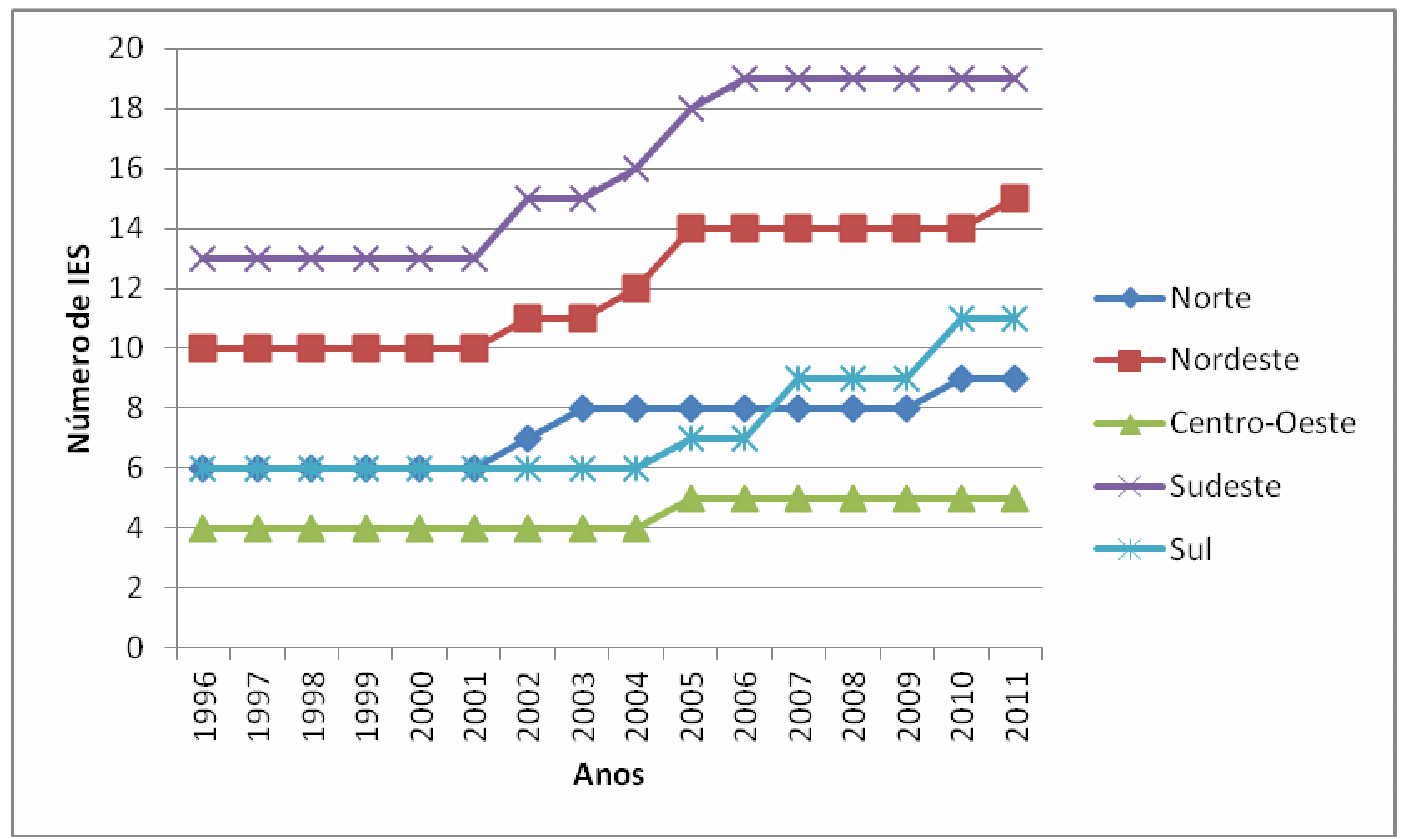

Fonte: da autora a partir de dados do Censo do Ensino Superior - INEP

Ainda que o número de Universidades Federais criadas seja importante, ela é parte da equação, assim, é importante avaliar ainda como se deu a distribuição das vagas e como elas se colocam em relação ao padrão de demanda que utilizamos para critério comparativo. 
Tabela 9: Número de vagas oferecidas em processos seletivos em Universidades Federais entre 2002 e 2010 nas macrorregiões

\begin{tabular}{lrrrrrrrrr} 
& $\mathbf{2 0 0 2}$ & \multicolumn{1}{c}{$\mathbf{2 0 0 3}$} & $\mathbf{2 0 0 4}$ & $\mathbf{2 0 0 5}$ & $\mathbf{2 0 0 6}$ & $\mathbf{2 0 0 7}$ & $\mathbf{2 0 0 8}$ & \multicolumn{1}{c}{$\mathbf{2 0 0 9}$} & $\mathbf{2 0 1 0}$ \\
\hline Brasil & 113.263 & 109.184 & 109.802 & 116.348 & 132.203 & 139.875 & 150.869 & 186.984 & 218.15 \\
Norte & 16.755 & 14.368 & 14.234 & 14.274 & 20.236 & 16.818 & 18.552 & 19.387 & 23.18 \\
Nordeste & 33.587 & 31.660 & 31.982 & 33.068 & 38.861 & 44.843 & 46.744 & 59.618 & 68.08 \\
Centro- & 13.260 & 15.083 & 14.041 & 14.761 & 14.991 & 15.553 & 16.888 & 20.836 & 25.43 \\
Oeste & & & & & & & & & \\
Sudeste & 32.509 & 30.862 & 32.145 & 32.145 & 35.736 & 39.024 & 43.278 & 54.746 & 62.23 \\
Sul & 17.152 & 17.211 & 17.397 & 17.397 & 22.379 & 23.637 & 25.407 & 32.397 & 39.21 \\
\hline & Fonte: INEP/MEC & & & & & & & &
\end{tabular}

Em um comparativo entre os dois períodos, vemos que a partir de 2007 tem um crescimento importante no número de vagas que continua com tendência de crescimento até o momento da consolidação dos dados analisados.

Gráfico 3: Evolução comparada do número de vagas em Universidades Federais em dois períodos: 1994-2001 e 2002-2009 no Brasil

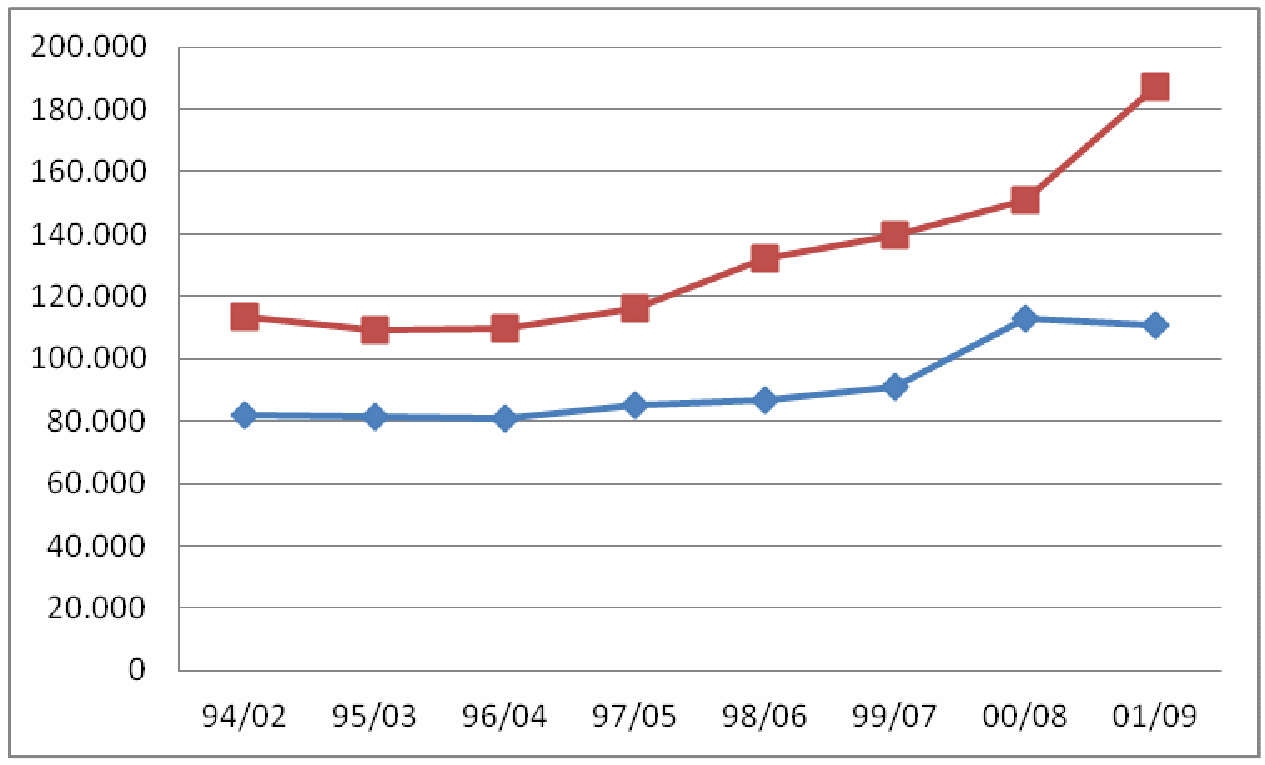

Fonte: INEP/MEC

1994-2001

$2002-2010$

Por fim, podemos visualizar como essas vagas estão distribuídas em relação à demanda (concluintes do ensino médio) para cada região.

Tabela 10: Distribuição de concluintes por vaga (oferecida em processo seletivo) entre as macrorregiões nos anos de 2002 e 2010 


\begin{tabular}{|c|c|c|c|c|c|c|}
\hline & \multicolumn{3}{|c|}{2002} & \multicolumn{3}{|c|}{2010} \\
\hline & vagas & concluintes & $\mathrm{c} / \mathrm{v}^{*}$ & vagas & concluintes & $\mathrm{c} / \mathrm{v}^{*}$ \\
\hline Brasil & 113.263 & 1.855 .419 & 16,38 & 231.530 & 1.825 .980 & 7,89 \\
\hline Norte & 16.755 & 127.190 & 7,59 & 24.633 & 154.415 & 6,27 \\
\hline $\begin{array}{l}\text { Nordeste } \\
\text { Centro- }\end{array}$ & 33.587 & 466.435 & 13,89 & 70.535 & 537.665 & 7,62 \\
\hline Oeste & 13.260 & 121.324 & 9,15 & 25.592 & 126.516 & 4,94 \\
\hline Sudeste & 32.509 & 884.109 & 27,19 & 68.672 & 774.809 & 11,28 \\
\hline Sul & 17.152 & 256.361 & 14,95 & 42.098 & 232.575 & 5,52 \\
\hline
\end{tabular}

A tabela 10 demonstra a comparação entre o número de concluintes por vaga no início e no fim do período analisado, sendo que, o número de concluintes não se alterou substantivamente, sendo até ligeiramente menor, item pendente de explicação pela literatura recente. Porém, podemos observar que nas regiões, houve grande mudança no que poderíamos chamar de cobertura das Universidades Federais. Podemos verificar a relação concluinte/vaga para cada região e perceber que elas diminuíram em relação ao início do período pelo menos pela metade na maioria das regiões (à exceção da região norte).

Podemos observar também que a proporção da demanda (concluintes do Ensino Médio) é maior na respectiva ordem: Sudeste, Nordeste, Sul, Norte e Centro-Oeste.

Além disso, na Tabela 5 e Gráfico 1 podemos observar como se dá a relação nesse período entre disponibilidade de vaga e demanda potencial. É visível que essa relação se altera a partir de 2006/2007 para todas as regiões demonstrando que houve significativa melhora nessa relação, mas não suficiente para equilibrar em termos comparativos.

\section{Conclusão}

Considerando a dimensão da distribuição regional da criação de universidades e da disponibilização de vagas nessas instituições federais, podemos ver que houve significativa mudança entre os dois períodos analisados. Até 2001 não houve criação de nenhuma nova universidade e no segundo período, foram de 39 a 59 (Gráfico 2), são 20 novas unidades, o que representa um avanço significativo, dado que a última criação de uma universidade federal 
registrada foi no ano de $1994^{4}$. Mas, ainda que um número substantivo de instituições tenha sido criada, ela pode não representar muito sem avaliar como as vagas estão distribuídas entre elas, por duas razões: a primeira é que a criação de uma instituição não garante que ela tenha um grande número de vagas, ela pode ser pequena; a segunda é que o REUNI, ponto de influência no período estudado também incentivou a criação de novos cursos, bem como a disponibilização de mais vagas em cursos existentes ${ }^{5}$.

Para tanto, o Gráfico 3 nos dá um referencial comparativo entre os dois períodos demonstrando que o número de vagas entre 2002 e 2010 teve crescimento relevante em comparação ao primeiro período.

A tabela 9 traz os dados desagregados por macrorregião, demonstrando que a região Nordeste (33.587 em 2002 para 68.082 em 2010), por exemplo, teve mais do que o dobro de vagas criadas no período, enquanto que a região sudeste ficou abaixo dessa porcentagem (32.509 em 2002 para 62.235 em 2010). Percebemos então que apesar da região nordeste já apresentar vantagem em relação aos números absolutos de vagas no início do período, essa vantagem aumenta no fim do período analisado.

Um ponto que cabe ressaltar aqui é que apesar de tratarmos as comparações entre as macrorregiões, ainda existem heterogeneidade dentro de cada região, item que não será analisado neste trabalho ${ }^{6}$.

Não bastando a situação das IES e das vagas, ainda poderíamos considerar a localização dos campi das instituições. Porém, dado o espaço curto para análise de tão vasto fenômeno e a falta de dados consolidados sobre os campi, apresentamos aqui o mapa apresentado pelo MEC da distribuição dos campi existentes até 2002, criados entre 2003 e 2010 e previstos a partir de 2011.

Figura 1: Mapa dos campi das Universidades Federais: existentes até 2002, criados entre 2003 e 2010 e previstos entre 2011 e 2014

\footnotetext{
${ }^{4}$ Consideramos a data do início do funcionamento das Universidades, dado que, por exemplo, a Universidade Federal do Tocantins foi criada em 2000, porém, somente passou a funcionar em 2003.

5 Para saber mais sobre como foi organizado o REUNI e suas características, ver Marques \& Cepêda (2012).

${ }^{6}$ Para entender melhor a situação da educação superior no nordeste ver Cepêda (2014).
} 


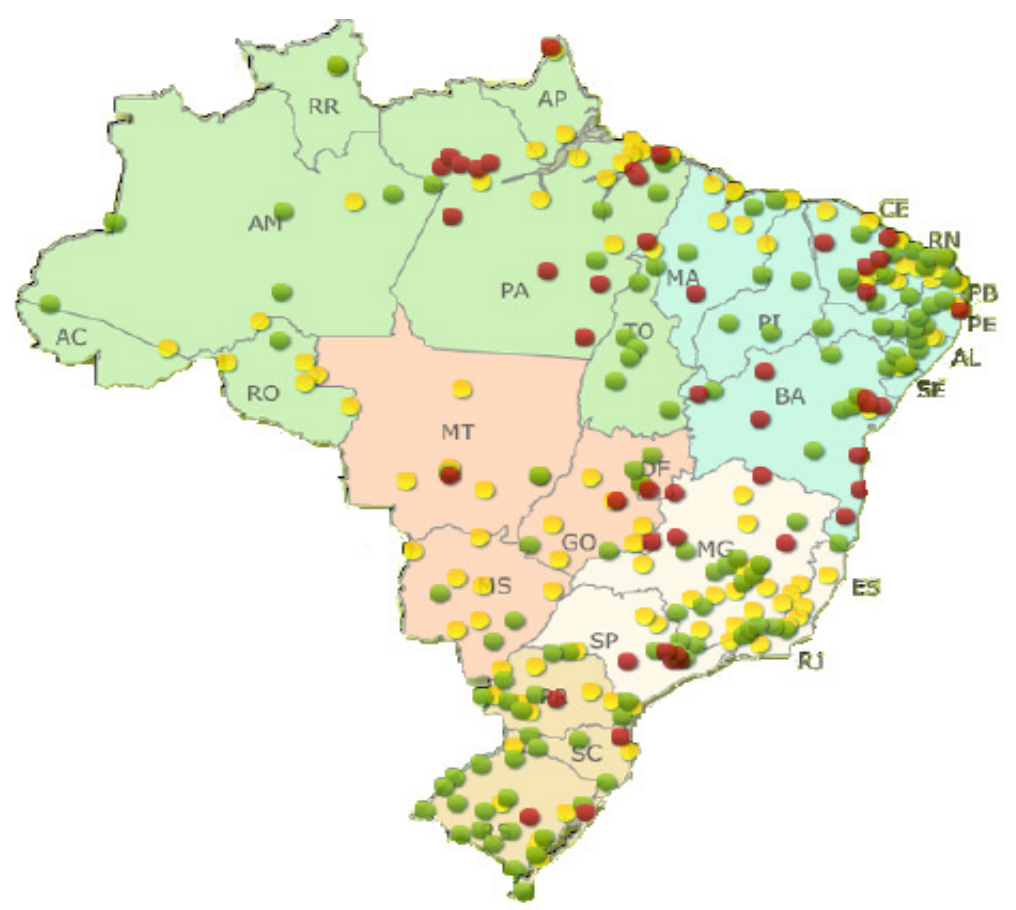

Campi existente até 2002

Campi criados entre 2002 e 2010

Campi previstos entre 2011 e 2014

Fonte: MEC (2013)

Para completar o quadro, ainda podemos olhar as Tabelas 4, 5, 8 e 10 para verificar um comparativo entre "oferta" e "demanda". Designamos como "oferta" a quantidade de vagas disponibilizadas pelas Universidades Federais e "demanda" potencial tanto o número de concluintes do ensino médio, independente da idade bem como a população entre 18-24 anos (total, não considerando o grau de escolaridade).

Nesse sentido, observamos no comparativo dos períodos entre concluintes do ensino médio por vaga disponibilizada em processo seletivo que houve substantiva redução dessa relação, porém, não é suficiente para caracterizar igualdade entre as macrorregiões, mas o suficiente para identificar uma tendência de distribuição equitativa entre elas.

Além dos resultados alcançados nesse artigo há uma vasta literatura que vem debatendo os limites, possibilidades, ganhos e perversões do programa.

Desde o início do programa há elementos que causam estranhamento. Depois da publicação do Decreto (6.096/07) e das Diretrizes gerais (julho/2007) foi dado até outubro para que as UFES elaborassem um projeto de atuação. Esse curto prazo mais a incerteza da garantia dos recursos (a disponibilidade deles 
estava condicionada ao orçamento do MEC) criou um clima de incerteza e motivou diversos setores das UFES ao não apoio do programa (SANTOS, 2009).

A meta colocada pelo programa de alcance de 18 alunos por professor e $90 \%$ de conclusão também não melhoram o cenário que, como aponta Léda e Mancebo (2009), tendem a levar à precarização do trabalho docente dado que, anos de não-investimento de associado ao programa que não contratou profissionais em número e qualificação suficientes, levaria a categoria a uma situação de trabalho pouco favorável.

Além disso, a expansão de instituições e vagas não é garantia, em absoluto da democratização do acesso ao ensino superior (NOGUEIRA, 2008). Ainda que haja políticas de ações afirmativas e de permanência estudantil, cabe questionar se a massa de alunos que está ingressando na educação superior, principalmente aqueles em situação de vulnerabilidade está ingressando da mesma forma em todas as áreas do conhecimento, ou se estes tem entrado em cursos de menor procura, menos status, continuando a reproduzir a diferença entre classe, raça e gênero.

A discussão sobre o tema também não se esgota com esses questionamento, porém, esperamos colocar algumas evidencias e iluminar o caminho para novas investigações sobre a temática.

\section{Referências Bibliográficas}

Abreu, Maria Aparecida Azevedo. (2010). “Educação: um novo patamar institucional". Revista Novos Estudos, v. 87.

Baer, Werner. (2002). A Economia Brasileira. 2a. Edição. ed. São Paulo: Nobel.

Barbosa, Gisele Heloise. (2012). "Democracia participativa no Brasil: a Câmara de Educação Superior do Conselho Nacional de Educação (1997-2007)". Dissertação de Mestrado. Programa de Pós-Graduação em Ciência Política, Universidade Federal de São Carlos, São Carlos.

Barreyro, Gladys Beatriz. (2008). Mapa do ensino superior privado. Brasília: INEP/MEC.

Bittar, Mariluce., \& Oliveira, João Ferreira., \& Lemos, Jandernaide. "Reforma da educação superior a partir dos anos 1990 e suas repercussões na região Centro-Oeste". Revista Teoria e Prática da Educação, v. 14, n. 2, p. 123-137.

Cepêda, Vera Alves. (2014). "Políticas de Desenvolvimento social e o Nordeste: um panorama sobre a expansão do Ensino Superior Público Federal recente". 
Em: Nascimento, Angela; Lima, Marcos Costa. O Nordeste brasileiro em questão: uma agenda para reflexão. Recife: UFPE; SUDENE, p.268-294.

Cepêda, Vera Alves. (2012). “Inclusão, democracia e novo-desenvolvimentismo um balanço histórico". Estudos Avançados, v. 26, n. 75.

Corbucci, Paulo Roberto. (2011). “Dimensões estratégicas e limites do papel da educação para o desenvolvimento brasileiro". Revista Brasileira de Educação v. 16 n. 48 set-dez.

Cunha, Luiz Antônio. (1980). A universidade temporã: o ensino superior da Colônia à era de Vargas. Rio de Janeiro: Civilização Brasileira.

Cunha, Luiz Antônio. (2003). "O Ensino Superior no octênio FHC". Educação e Sociedade (Campinas), v. 24, n. 82, p. 37-61.

Durham, Eunice. (2003). "O Ensino superior no Brasil: O público e o privado". Documento de trabalho NUPPES. São Paulo.

Gremaud, Amaury Patrick., \& Vasconcellos, Marco Antonio Sandoval de., \& Toneto JR. , Rudnei. (2007). Economia Brasileira Contemporânea. 6a. Edição. ed. São Paulo: Atlas.

Ipea. (2010). Perspectivas do desenvolvimento: Efeitos econômicos dos gastos sociais no Brasil. Brasília.

Marques, Antonio Carlos Henriques., \& Cepêda Vera Alves. (2012). “Um perfil sobre a expansão do ensino superior recente no Brasil: Aspectos democrático e inclusivos". Perspectiva, São Paulo, v. 42, p. 161-192, jul./dez.

Ministério da Educação. (2013). “Expansão da Educação Superior e Profissional e Tecnológica: Mais formação e oportunidade para os brasileiros". Disponível em:

http://portal.mec.gov.br/expansao/images/APRESENTACAO_EXPANSAO_EDUC ACAO_SUPERIOR14.pdf Acesso em 20 de junho de 2013.

Nogueira, Jaana Flávia Fernandes. (2008). “Reforma da Educação Superior no Governo Lula: Debate sobre ampliação e democratização do acesso". Dissertação de Mestrado. Faculdade de Educação, Universidade de Brasília, Brasília.

Nunes, Edson. (2012). Educação superior no Brasil: estudos, debates, controvérsias. Rio de Janeiro: Garamond.

Nunes, Edson. (2007). “Desafio estratégico da Política Pública: o ensino superior brasileiro". Revista de Administração Pública, v.41, n. número especial. 
Peres, Thais Helena de Alcântara. (2010). “Educação Superior, emprego e renda: uma relação problemática". Tese de Doutorado. Faculdade de Filosofia, Letras e Ciências Humanas, Universidade de São Paulo, São Paulo.

Pinto, José Marcelino Rezende. (2004). "O Acesso à educação Superior no Brasil". Educação e Sociedade, Campinas, v. 25, n. 88, p. 727-756, Especial, out.

Pochmann, Marcio. (2004). “Educação e Trabalho: como desenvolver uma relação virtuosa? " Educação e Sociedade, Campinas, vol. 25, n. 87, p. 383-399, maio/ago.

Santos, Bruno Lima Patrício dos. A representação do REUNI no debate do ensino superior enquanto direito. Educação em Revista, Marília, v. 10, n. 1, p. 29-44, jun.

Soares, Maria Susana Arrosa. (2002). A educação superior no Brasil. Porto Alegre: IESALC/UNESCO. 